Clemson University

TigerPrints

$10-2020$

Finding community and overcoming barriers: experiences of queer and transgender postsecondary students in mathematics and other STEM fields

Elizabeth Kersey

Matthew Voigt

Follow this and additional works at: https://tigerprints.clemson.edu/engineeringed_pubs

Part of the Higher Education Commons, and the Science and Mathematics Education Commons 
Finding community and overcoming barriers: experiences of queer and transgender postsecondary students in mathematics and other STEM fields

\section{Elizabeth Kersey \& Matthew Voigt}

Mathematics Education Research Journal

ISSN 1033-2170

Math Ed Res J

DOI 10.1007/s13394-020-00356-5 
Your article is protected by copyright and all rights are held exclusively by Mathematics Education Research Group of Australasia, Inc.. This e-offprint is for personal use only and shall not be self-archived in electronic repositories. If you wish to self-archive your article, please use the accepted manuscript version for posting on your own website. You may further deposit the accepted manuscript version in any repository, provided it is only made publicly available 12 months after official publication or later and provided acknowledgement is given to the original source of publication and a link is inserted to the published article on Springer's website. The link must be accompanied by the following text: "The final publication is available at link.springer.com". 


\title{
Finding community and overcoming barriers: experiences of queer and transgender postsecondary students in mathematics and other STEM fields
}

\author{
Elizabeth Kersey ${ }^{1}$ (D) Matthew Voigt $^{2}$ (D)
}

Received: 31 March 2020 /Revised: 21 August 2020 / Accepted: 5 October 2020

Published online: 19 October 2020

(C) Mathematics Education Research Group of Australasia, Inc. 2020

\begin{abstract}
Although there is little research on the experiences of queer and/or transgender postsecondary students in science, technology, engineering, and mathematics (STEM) fields, we can infer from current literature that these subjects may be less welcoming than the humanities and social sciences. We conducted two studies to investigate this possibility: (1) a narrative inquiry study with postsecondary transgender students and (2) a grounded theory narrative study with undergraduate queer students. Transgender students who had transitioned indicated that they were subjected to lower expectations when presenting as female, but transgender women experienced this change as positive, since their treatment by others was no longer accompanied by gender dysphoria. Queer students experienced mathematics and other STEM fields as objective and independent of identity, yet simultaneously exclusionary of their queer identities. Many of the queer students in these studies found strength and resilience in queer communities, but there were some transgender women who did not view being queer as a central facet of their identity and did not feel the same sense of community. In general, those who were more gender-nonconforming felt a greater need for community with other queer people. We draw connections between gender category oppression and gender transgression oppression, and suggest strategies to make academic STEM fields more inclusive of queer and transgender students.
\end{abstract}

Keywords Queer·Transgender · LBTQIA · STEM · Mathematics

Elizabeth Kersey

kerseybetsy@gmail.com

Matthew Voigt

mkvoigt@gmail.com

1 School of Mathematical Sciences, University of Northern Colorado, Greeley, CO, USA

2 Center for Research in Mathematics and Science Education, San Diego State University, San

Diego, CA, USA 
In an increasingly globalized and diverse society, there is mounting pressure on educators to create learning opportunities that are enriching and inclusive for all students. Researchers in mathematics education have recognized the need to move beyond the cognitive dimension of learning and investigate how communities, culture, and social processes influence learning (e.g., Cobb and Yackel 1996; Forman 2003). This movement has been so prolific that some have deemed it the "social turn" in mathematics education research (Lerman 2000). However, there continues to be growing pressure from within the community, suggesting that even the "social turn" has not gone far enough to address issues of identity, power, and agency, all of which have dramatic effects on the learning and well-being of students (Gutiérrez 2013; Nasir and de Royston 2013). As such, there has been a growing effort within science, technology, engineering, and mathematics (STEM) education to broaden participation, address equitable outcomes, and promote inclusive learning environments for students with an array of identities and backgrounds. At the same time, educational research, institutional programs, and policies to support students with a queer identity in undergraduate mathematics remain largely underdeveloped and undertheorized. By students with a queer identity, we mean students who identify as lesbian, gay, bisexual, transgender, and/or in other ways queer (LGBTQ+) because of their sexual identity or gender identity (Kumashiro 2001).

In this article, we seek to address this gap in the literature by documenting the experiences of queer students in STEM environments and identifying the resources that can foster inclusive experiences for queer STEM-intending students. Specifically, we present two studies that occurred with queer-identifying STEM postsecondary students. In the first study, we highlight experiences of gender-based privilege and oppression in STEM for transgender and/or gender-nonconforming students. In the second study, we highlight how the coming out process is navigated by queer students and how the perceived nature of STEM can contribute to exclusionary experiences. We conclude the paper by drawing comparisons across the two studies to provide recommendations for future research and instructional practice in postsecondary STEM (and particularly mathematics) classrooms.

\section{Theoretical framework}

The theoretical lenses we utilized in these studies are critical post-structuralism, feminism, and queer theory. We lay critical post-structuralism as the foundation by using post-structural concepts (discourse, subjectivity, situatedness, etc.) to examine power relations. Feminism is a broad term that encompasses a wide variety of frameworks, but the feminism used here is post-structural feminism, with which we focus on gender-based privilege and oppression. Queer theory is a post-structural theory that typically focuses on sexuality and sometimes gender, but it is a more extensive theory that is described in greater detail below.

\section{Critical post-structuralism}

Post-structuralism is a postmodern theory based in the writings of Foucault and Derrida (Johnson and Christensen 2014). Post-structuralists emphasize discourse as the 
mechanism through which we construct our understandings. Discourse does not refer simply to written or spoken text, but encompasses a myriad of human activities, including "institutions, actions, words, and taken-for-granted ways of interacting and operating" (Gutiérrez 2013, p. 43). Because discourses change with time and setting, all knowledge is considered subjective and historically situated (Walshaw 2004). The dominant culture has the most influence in creating discourse and thus knowledge, but which culture is dominant varies greatly depending on the setting. For instance, the dominant culture on a college campus as a whole is likely to be very different from the dominant culture within LGBTQ+ student resource centers on campus.

Because post-structuralists consider all knowledge to be subjective, constructs such as woman or gay are also socially constructed (Walshaw 2001). The constructed nature of social concepts is counter to essentialist tendencies in which, for instance, there is a common central experience that makes one a woman. Post-structuralists are opposed to biological essentialism as well as identity essentialism; there is no more certainty to being physically female than there is to identifying as a woman. Post-structuralists often use tools such as discourse analysis to examine the ways that hegemonic structures are (re)produced. For instance, Barnes (2000) examined the types of masculinity performed in a mathematics classroom, what that meant for all students, and how those types of masculinity interacted with how much power students in various groups held.

We believe that adding a critical dimension to post-structuralism can help us engage with the lived realities of marginalized people (Stinson and Bullock 2012). Adding a critical dimension to post-structuralism entails a focus on relationships of power, particularly on how dominant discourses lead to the oppression or disenfranchisement of some groups, and how people in those groups exercise agency by resisting and transforming those discourses. Our primary focus in this article is discourses surrounding gender, sexuality, mathematics, and STEM, but since identities are always intersectional, we also consider other constructs that influence those discourses.

Post-structural feminism We utilize a post-structural feminist framework for this study, largely because we reject gender essentialism. Other feminist scholars in mathematics education have argued for a feminine perspective on mathematics teaching (Boaler 1997) or created mathematical spaces where femininity is the norm (Anderson 2005). While these types of studies are valuable, post-structural feminists would critique the alignment of women with femininity, as well as the raced, classed, and heterosexual femininity at play. A post-structural researcher, instead of taking the concept of femininity for granted, could look at the ways that gender is brought into play in the mathematics classroom, what that means for the members of that community, and how those norms are (re)enforced or resisted. An exemplar of this type of analysis is Walshaw (2001), who examined how girls drew from general cultural discourses about gender to claim or resist these narratives within the mathematics classroom.

Transgender people, particularly transgender women, have a complex relationship with gender norms. On the one hand, trans women are "encouraged and sometimes required to adopt the traditional definition of femininity in order to be accepted and legitimized by the medical community" (Koyama 2003, p. 245). The appeal of traditionally feminine norms may be a reason for them to transition. On the other hand, no one should be required to validate their womanhood by performing 
femininity. Thus, we must recognize that gender norms have complex effects on individuals and that there are social consequences for transgressing those norms. Some transfeminist scholars have rejected the one-size-fits-all view of feminism, oppression, and marginalization and instead have advocated for a more holistic approach to feminism (Serano 2013). Thus, we turn to queer theory to help us understand the complexity of gendered relations.

\section{Queer theory}

As one might infer from its name, queer theory originated in gay and lesbian studies, but the two are by no means synonymous. One may easily study gay participants with a positivist lens, while queer theory is a broader theoretical framework centered around disrupting norms that can be applied to a wide variety of subjects (Gamson 2000). Queer theorists refuse to accept exclusion by or assimilation into normative society, instead protesting the very existence of social norms. Queer theory is a post-structural theory, and as such, queer theorists are concerned with the power of discourse. Queer theory is even more anti-essentialist than post-structural feminism; where a poststructural feminist might be able to define what woman means in one particular time and place, a queer theorist tends to resist labels and static identities. As Britzman (1995) states, "every sexual identity is an unstable, shifting, and volatile construct, a contradictory and unfinalized social relation" (p. 68, emphasis in original). We contend that this characterization of identity as dynamic applies to all identities, not just sexual identities. We avoided placing boundaries around categories like STEM, queer, or transgender in our studies and instead opted to let our participants decide whether those words applied to them or not.

Mendick (2006) describes disrupting binaries as the "raison d'être" of queer theory. Binaries are social constructions of oppositional categories that often hold social power. Examples of powerful binaries we seek to disturb are male/female, gay/straight, rational/emotional, and others. Queer theorists also want to trouble the notion that binaries align neatly with each other (Mendick 2006). For instance, the binaries man/ woman, masculine/feminine, and independent/cooperative are often assumed to line up. We dispute this alignment, as well as the existence of these binaries. More generally, queer theory is about disrupting social norms. The gender binary is a powerful social norm we seek to disrupt. One method by which we disrupt the gender binary is by telling stories about those who do not fit into this binary and learning from narratives outside of the dominant culture.

\section{Unpacking identity}

Because of our queer theoretical perspective, we reject the notion of well-defined static identities. For instance, we know that sexuality is often defined based on one's gender as well as the gender of those to whom one is attracted. Additionally, it is a fluid identity that can change regularly or over time. We can also separate sexual attraction from romantic attraction. For gender, we can differentiate between gender identity, gender presentation, and gender attribution, all of which are subject to change depending on the context. For both gender and sexuality, there are a myriad of microidentities one might 
choose, such as genderfae, lithromantic, or pomosexual. ${ }^{1}$ As queer theorists, we encourage this proliferation of identities while not enforcing rigid definitions to any of them. We are reluctant to use binaries such as gay/straight, cisgender/transgender, or even binary/nonbinary. However, as scholars, we know that such distinctions are necessary in order to make meaningful comparisons. While we endeavor to portray our participants as whole people not defined by labels, when they choose such labels on their own, we feel justified in using those to create (dynamic, fluid) categories for analysis.

While we aim to foreground different aspects of queerness, we contend that sex and gender are inseparable and interrelated. As such, we use the terms sex/male/ female interchangeably with gender/man/woman, respectively. This is a conscious decision and does not stem from a naïve belief that there is no difference between the two. Rather, it is because we recognize that sex roles and gender roles are closely intertwined and to distinguish between the two is to create a false binary. As Butler (1999) argues, "Perhaps this construct called 'sex' is as culturally constructed as gender; indeed, perhaps it was always already gender, with the consequence that the distinction between sex and gender turns out to be no distinction at all" ( $p$. 7). Another reason for this decision is that using sex and gender terminologies interchangeably is typical among transgender communities. For instance, Trans Student Educational Resources (2020) defines gender identity as “one's internal sense of being male, female, neither of these, both, or other gender(s)" (Basic Terminology). Therefore, most of the participants used this language as well. If we need to specify a specific aspect of gender or sexual attraction, we use more specific terms, such as sex assigned at birth, gender identity, physical attraction, or gender presentation.

\section{Queer in STEM literature}

When it comes to marginalized sexual and gender identities, the research literature remains largely in the closet; researchers seldom address the impact or representation of queer individuals in mathematics. While research at the intersection of queerness and mathematics is still emergent, there exists a larger research base and theory development in the sciences and engineering more broadly. Although our focus is on mathematical environments, we turn to STEM literature to contextualize and understand the experiences of queer people in mathematics. Sexual identity is rarely included on national surveys or college admission applications; therefore, there is little indication if queer students are underrepresented in STEM fields in the same way as women and students of color. However, there is evidence that LGBTQ+ individuals may be underrepresented in STEM fields, as they constitute a smaller percentage of the workforce at STEM-related federal agencies $(2.7 \%)$ than at non-STEM federal agencies (3.1\%; Cech 2015).

Most studies examining the experiences of postsecondary queer students are focused primarily on campus climate (e.g., Wimberly 2015). We know from these studies that

\footnotetext{
${ }^{1}$ Genderfae is a type of genderfluidity that is never male or masculine. Someone who is lithromantic experiences romantic attraction but does not desire that attraction to be reciprocated. Someone who is pomosexual does not wish to categorize their sexuality.
} 
queer undergraduate students report high rates of harassment on campus and fear getting a bad grade because of a hostile classroom environment (Wimberly 2015). The hostile environment of academia toward queer students may limit their abilities to reach their academic potential, as students report that a positive campus climate contributes to their academic success (Rankin et al. 2010). Academic performance is also impacted by the "coming out" process, through which one must make daily decisions about revealing one's sexuality in the classroom (Lopez and Chims 1993).

Bilmoria and Stewart (2009) examined the academic climate for queer faculty in science and engineering, which participants characterized by "overt hostility..., invisibility, interpersonal discomfort, and pressure to 'cover' their sexuality" (p. 85). A majority of queer individuals in STEM workplaces, including academia, described their workplace as safe for queer people (92\%), yet only a minority $(43 \%)$ were out to at least half their colleagues (Yoder and Mattheis 2016). Those participants in STEM fields with better representation of women reported higher degrees of openness. Individuals from the fields of earth science, engineering, mathematics, and psychology reported the least amount of being out to their colleagues (Yoder and Mattheis 2016). One transgender mathematician in academia pointed to issues related to health care, changing articles published under their "dead name," and transitioning in front of students, which all contributed to carrying around dread and psychological anguish in everyday tasks (Lamb 2017). In part, this hostility is fuelled by the cultural norms within STEM fields that constrain diverse forms of expression or attitudes (Grunert and Bodner 2011). In lieu of these findings, educators need to support students' identity development through the "queering" of mathematics (Mendick 2006; Dubbs 2016) in order to make it less male-centric and to counter the absolutism and binary construction of mathematics. This can include questioning the construction of gender and sexuality in the formulation of mathematics problems (Rands 2009b), questioning the very nature of mathematics as a well-defined set of deductive principles (Davis and Sumara 2000), and/or queering mathematics pedagogy to reject the normative (Dubbs 2016).

Marginalization due to sexuality and gender identity might be felt more acutely within STEM-related courses, where issues of gender and sexuality are rarely included in the curriculum (Bilmoria and Stewart 2009; Pryor 2015; Cooper and Brownell 2016). Queer undergraduate students in STEM fields are $8 \%$ less likely than their straight cisgender peers to remain in STEM, even when controlling for various characteristics determined to predict retention (Hughes 2018). Adolescent same sexattracted boys were more than $40 \%$ less likely to complete Algebra II and chemistry than their opposite sex-attracted peers, a trend that was not present for foreign language courses (Pearson et al. 2007). Based on these findings, it may be that something is "unique about mathematics and science that makes them more intimidating than other subjects" (Pearson et al. 2007, p. 113) for queer students.

\section{Dimensions of gender oppression}

Rands $^{2}$ (2009b, 2012) proposed a gender-complex approach for research with transgender participants in mathematics education, though its potential applications are much broader. This approach is a way of conceptualizing gender-based oppression as

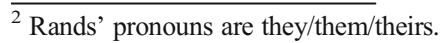


composed of two dimensions. The first dimension, gender category oppression, refers to the degree of privilege or oppression one experiences based on the gender category to which one is presumed to belong, whether man, woman, or nonbinary. The second dimension, gender transgression oppression, refers to the degree of privilege or oppression one experiences based on how well a person fits into their presumed gender category. For an example, consider a man who presents as feminine. Because he is a man, he would experience gender category privilege. But because he is perceived as feminine (and not female), he would experience gender transgression oppression. These experiences are based primarily on how one is perceived, but the systemic exclusion of the possibility of nonbinary genders is an example of gender category oppression that does not depend on others' perceptions. Authorl (2018) modeled this concept with a plane consisting of one axis for gender category privilege/gender category oppression and another (perpendicular) axis for gender conformity privilege/gender transgression oppression (see Fig. 1). We refer to this as the Dimensions of Gender Oppression (DGO).

These two axes are not necessarily independent from each other. For example, the type and degree of gender transgression oppression will be quite different for a masculine woman than for a feminine man. A person's position is not fixed either; one's gender presentation can change, and different audiences can interpret a gender presentation in different ways and have different reactions to that. Thus, this instrument is best used qualitatively, where participants have a large degree of freedom with how they use and interpret the diagram and can explain what they mean. This chart is focused on gender because of the research focus and the fluidity of gender over time, particularly for transgender people. However, there are a myriad of intersecting perpendicular axes representing privilege and oppression based on race, class, religion, etc. Another reason this instrument should be used qualitatively is to better understand the impact of these intersectional factors. In study 1, this instrument was described to participants as having male privilege at the right of the horizontal axis and female oppression, or sexism, on the left of the horizontal axis. However, we now feel that it is

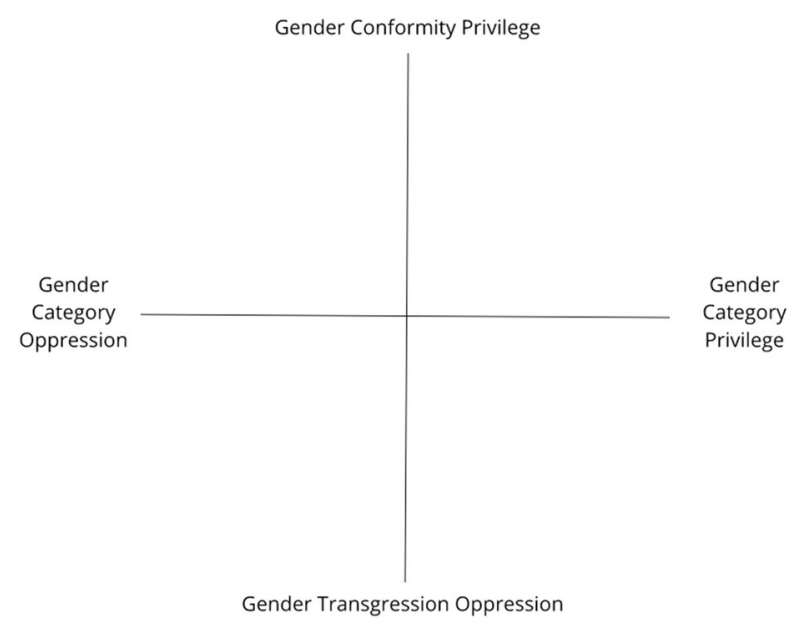

Fig. 1 Dimensions of Gender Oppression (DGO) chart used in study 1 
better to let participants decide whether presenting as female or nonbinary would put one farther to the left on the horizontal axis.

\section{Methods}

In this article, we discuss two studies in which our goal was to unpack and understand the experiences of queer students in STEM. In the first study, we foreground the impact of gender identity for queer students in STEM. In the second study, we foreground the impact of sexual identity for queer students in STEM. By drawing together these two studies, we are able to highlight and problematize the nature of queer experiences in STEM. The data for both studies were collected as part of doctoral dissertations (Kersey 2018; Voigt 2020).

\section{Researcher positionality}

In this section, we provide a brief description of our own identities as they impact our work, as these inevitably influence all decisions in the research process. Elizabeth Kersey, the researcher for study 1, is a White, cisgender, aromantic woman with a disciplinary background in mathematics and education with an emphasis on critical gender studies. Her primary research interest is queering gender research in mathematics education. Matthew Voigt, the researcher for study 2, identifies as a White, cisgender, gay man and is a first-generation college student with a disciplinary background in mathematics and psychology. His primary research interest is examining the experiences and institutional resources for queer undergraduate STEM students.

Our positionality informed both the data collection phase and our interpretation of the lived experiences of our participants. In terms of the data collection, our own queer identities contributed to our ability to effectively recruit participants through our social networks and communities and facilitated rapport building with our participants. At the same time, we also acknowledge the difference in our identities (e.g., gender identity, sexual identity, racial identity, etc.) that necessitated building knowledge and familiarity with identities we do not hold. In the interpretation and communication of our results, we used member checking as a way to ensure the authenticity of the lived experience and used bracketing to understand our own beliefs and lived experiences as queer researchers apart from those of our participants.

\section{Study 1: Postsecondary transgender students in STEM}

Participants were eligible for this study if they self-identified as transgender and/or gender-nonconforming and if they had been a student in a postsecondary STEM field within the last 12 months. Participants determined whether their field counted as STEM. Participants were current or former graduate and undergraduate students. Seven participants were recruited through snowball sampling (Winkle-Wagner 2010). Using a narrative inquiry methodology (Clandinin and Connelly 2000), each participant completed a journal prompt and three semi-structured interviews of up to $90 \mathrm{~min}$. The first interview was focused on their life before college (past), the second on their life after entering college (present), and the third on looking to the future and reflecting on the 
past (Seidman 2013). Interviews were focused on participants' experiences in mathematics and other STEM fields, their gender identity and presentation and related experiences, and connections between these topics. During the first and second interviews, participants were asked to chart their position on the DGO. In the third interview, participants were asked to reflect on the use of the instrument. Participants chose their own pseudonyms. Table 1 contains information about each participant. Some readers may feel uncomfortable with Weirdo's pseudonym, but that was her choice, and reclaiming a slur is very much in the spirit of queer theory (Butler 1993; Brontsema 2004). Data were analyzed through the process of restorying described by Ollerenshaw and Creswell (2002) using the three-dimensional space of narrative inquiry (Clandinin and Connelly 2000).

\section{Study 2: Undergraduate queer students in STEM}

Participants were eligible for this study if they identified as LGBTQ+ and if they were an undergraduate pursuing a STEM field. Participants were recruited from two queer-friendly large public universities (Pride Index 2017) in the USA that have Out in STEM (oSTEM) student organizations. oSTEM is a national society dedicated to educating and fostering leadership for queer communities in the STEM fields (oSTEM 2020). Four undergraduate students, Amber, Charles, Jenny, and Juan, agreed to participate in the study and were offered nominal financial compensation. A summary of each of the participants giving their identities, pronouns used, and STEM major is displayed in Table 2. Each student participated in a roughly 1-h semi-structured interview (Ginsburg 1997) to target information about (a) their experiences as a queer student in STEM, (b) how they perceive the nature of STEM, (c) favorite courses and instructors, (d) description of the "coming out" processes, (e) advice for other students, and

Table 1 Summary of study 1 participant identities, pronouns, and majors

\begin{tabular}{|c|c|c|c|}
\hline Pseudonym & Age and identities & Pronouns & Major(s) \\
\hline Amy & 23, White, undergraduate & She/her/hers & $\begin{array}{l}\text { Electrical Engineering (former), } \\
\text { Computer Technology (current) }\end{array}$ \\
\hline Hannah & $\begin{array}{l}\text { 27, White and Hispanic, Costa } \\
\text { Rican, doctoral student }\end{array}$ & She/her/hers & Electrical Engineering \\
\hline Kayla & 25, White, Master's student & She/her/hers & $\begin{array}{l}\text { Aviation Technology (Bachelor's), } \\
\text { Aviation Management (Master's) }\end{array}$ \\
\hline Peter & $\begin{array}{l}\text { 27, White, doctoral student, } \\
\text { nonbinary, autistic }\end{array}$ & They/them/theirs & $\begin{array}{l}\text { Mathematics (Bachelor's, Master's), } \\
\text { Mathematics Education (Doctorate) }\end{array}$ \\
\hline Reed & $\begin{array}{c}\text { 21, White, undergraduate, } \\
\text { nonbinary, genderfluid }\end{array}$ & They/them/theirs & $\begin{array}{l}\text { International Agronomy, Women's } \\
\text { Studies }\end{array}$ \\
\hline Violet & $\begin{array}{l}\text { 25, White, graduated with } \\
\text { Master's } \\
\text { degree, autistic, mentally ill, } \\
\text { gender-nonconforming (trans) } \\
\text { woman }\end{array}$ & They/them/theirs & Environmental Science \\
\hline Weirdo & 21, Asian, former undergraduate & She/her/hers & Computer Technology \\
\hline
\end{tabular}


(f) the completion of two mathematical tasks. Similar to study 1, the participants were given the option to choose a pseudonym. Drawing on the methods of grounded theory and narrative analysis (Corbin and Strauss 1990; Strauss and Corbin 1994), open coding was used to assign codes to the transcripts that represented the phenomenon of being queer in STEM. A constant comparative method was used to assign axial codes and group the codes according to emerging themes to develop a theory of queer experiences in STEM.

\section{Cross-case analysis}

Study 1 and study 2 were conducted by both authors in isolation of each other. Although the focus and methods of each study were different, combining these studies added evidential support to understand the experience of queer students in mathematical environments. After the data collection and analysis phase of each respective study, we identified emergent themes within our own datasets, and then cross-referenced these themes to identify areas of congruence across both studies (Borman et al. 2012). Once cross-cutting themes were identified, we returned to our original datasets through an iterative process to identify confirmatory and contradictory evidence to build and draw complexity within the identified themes (Yin 2009).

\section{Results}

In the following section, we present four main areas of results from the two studies to highlight the experiences of queer and transgender students in STEM. We start by discussing students' experiences of gender-based privilege and oppression as conveyed through the DGO. We then describe ways to understand how queer students "come out" in STEM classrooms, followed by a discussion on how the nature of STEM influences their experiences. We conclude by highlighting strategies that help foster support and resiliency for queer students in STEM.

Table 2 Summary of study 2 participant identities, pronouns, and STEM major

\begin{tabular}{|c|c|c|c|}
\hline Pseudonym & Affiliated identities and communities & Pronouns & Major \\
\hline Amber & $\begin{array}{l}\text { Gay, gender fluid, African } \\
\text { American, YouTuber }\end{array}$ & $\begin{array}{l}\text { They/them/theirs or } \\
\text { he/him/his }\end{array}$ & $\begin{array}{l}\text { Former Applied Math, } \\
\text { Current Interdisciplinary } \\
\text { Studies }\end{array}$ \\
\hline Charles & $\begin{array}{l}\text { Straight, trans, Canadian } \\
\text { citizen, German proficient }\end{array}$ & $\mathrm{He} / \mathrm{him} / \mathrm{his}$ & Mechanical Engineering \\
\hline Jenny & $\begin{array}{l}\text { Bisexual, gender fluid, fem identity, } \\
\text { musician (violinist) }\end{array}$ & $\begin{array}{l}\text { She/her/hers or } \\
\text { they/them/theirs }\end{array}$ & Physics \\
\hline Juan & Gay, male, Mexican American & $\mathrm{He} / \mathrm{him} / \mathrm{his}$ & $\begin{array}{l}\text { Pre-med (Biochemistry and } \\
\text { Cellular Biology) }\end{array}$ \\
\hline
\end{tabular}




\section{Gender-based privilege and oppression}

This theme was predominantly present in study 1 ; however, we also draw on evidence from study 2 to add additional perspectives. We utilized a queer perspective to integrate these findings and trouble the boundaries between the two studies. As described above, the DGO was used in study 1 in interviews with each participant. This instrument served to generate both a visual depiction of their experiences and a context in which to talk about what their experiences had been with each type of privilege and/or oppression. A few participants were reluctant to claim their experiences as oppression, which likely affected where they plotted themselves. Discrimination may be a better term to use in future studies. One exception to this was Reed, who as a double major in women's studies had a thorough background with this terminology. Reed's DGO for their undergraduate years is given in Fig. 2. Reed was assigned female at birth and identified as a tomboy for much of their childhood. Beginning in secondary school, Reed put more effort into presenting as very feminine, which continued through the beginning of their undergraduate studies. They then became gradually less gender-conforming. Describing their path on the DGO, they said, "It's like a question mark, cool. Just like my gender. Great." However, the DGO representation is not a unidirectional path. Rather, Reed said that they "move along this little friend here, depending on the day."

While Reed did describe several ways in which they experienced gender transgression oppression, most of their experience with gender category oppression was with letting go of internalized oppression.

Oftentimes I present as more masculine. Largely because I'm doing stereotypically masculine things, like asserting myself, being confident, taking up space unapologetically, things that are coded as masculine, but really should not be, but. Sexism. ... I'm not afraid of conflict as a person. I know a lot of feminine people are very afraid of confrontation, and I think that's because of the society in which we live, and the women are told, you cannot be confrontational.

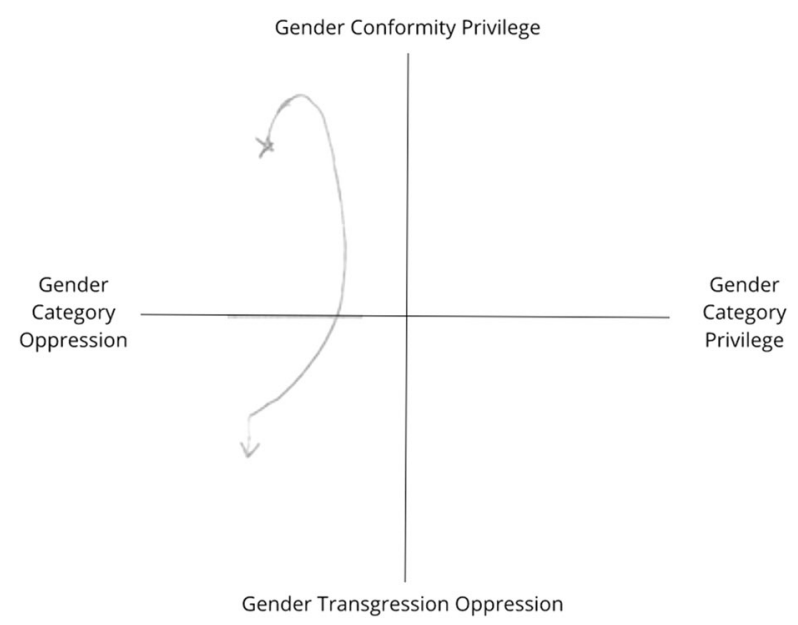

Fig. 2 Reed's placement on the DGO during their undergraduate years 
Most of what Reed described is unlearning the mannerisms that are apologetic for one's own existence that girls often learn in childhood. Note that Reed acknowledged that owning one's own power is considered masculine, but they disagreed with this characterization. As a result of acting in this manner, Reed experienced a degree of gender transgression oppression. For instance, "If I'm speaking with a confidence, and I'm speaking with a voice that recognizes its own power, oftentimes I get weird looks. ... Where folks are like, why are they so bitchy? Why are they so loud?" Thus, even though Reed experienced more gender transgression oppression, this was largely an improvement over their internalized gender category oppression. This change in ownership in personal power is not reflected in the graph because Reed interpreted it to reflect how they were perceived by others.

Letting go of internalized oppression was also an important experience for Amy and Hannah, although they needed to let go of internalized gender transgression oppression rather than gender category oppression. Hannah's charting of her experiences on the DGO (see Fig. 3) does reflect this change in her internal restrictions. As a child assigned male at birth, Hannah was frequently bullied for being too feminine. She internalized this pressure to the point where she "didn't ever give myself permission to be feminine." She experienced a feeling of great relief and freedom once she let go of that pressure: "Letting go of all that oppression and stuff has been great. Because I don't feel I have to conform to a specific stereotype of being manly anymore." After transitioning, Hannah did describe experiencing some gender category oppression in her colleagues taking her less seriously: "It's a lot easier to get talked over now, like people will just talk over me all the time." These experiences are not reflected on her chart because she also noticed many improvements in her interactions with others:

The way that people interact with me now is so different and so much better. I think I touched on it a little bit last session, but it's the little differences in between how people treat men and women in general, I feel more embraced, like people will smile more, are more caring, more empathetic, like they talk a lot more, like they are not scared of me, which was something that I hated before. It's not seen as creepy if I compliment someone anymore, which is awesome. ... I just feel a lot more included in the group, as part of the group, and as a person, and probably because I'm allowing myself to be part of the group, too.

For Hannah, the positive changes she experienced, both internally and in her interactions with others, outweighed the decrease in respect from her colleagues: "I can deal with that, with all the positives, like, it's no big deal."

Amy transitioned abruptly from presenting male nearly all the time to presenting female nearly all the time. When she first transitioned, she did not conform to gender norms as a woman, but she was gradually able to conform more to female gender norms and thus increase her gender conformity privilege. Due to the suddenness of her transition, the arrows in Amy's DGO (see Fig. 4) indicate a chronology, but the points that represent her experiences are discrete points. Amy felt as though she needed to work harder to achieve the same academic recognition when presenting as female than when she was presenting as male. The suddenness of her transition made these 


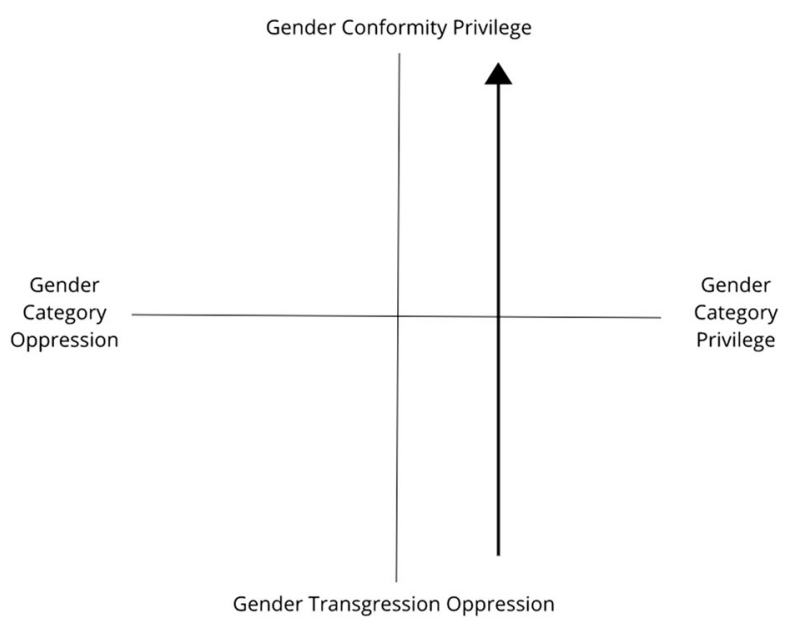

Fig. 3 Hannah's placement on the DGO since secondary school

differences even more noticeable. As with Hannah, however, she felt that this was a small price to pay for her transition. The following is an excerpt from Amy's journal:

Despite having experienced male privilege in the past, it was VASTLY outweighed by the torment of gender dysphoria. In some ways, I also suffered from male privilege prior to transition as well. Not only are there these unobtainable [male] beauty standards, but my body cannot ever even get close to many of them. That kind of torment weighed heavily on me and only grew worse the farther into puberty I went. This is also what I feel is especially important to include in the published findings.

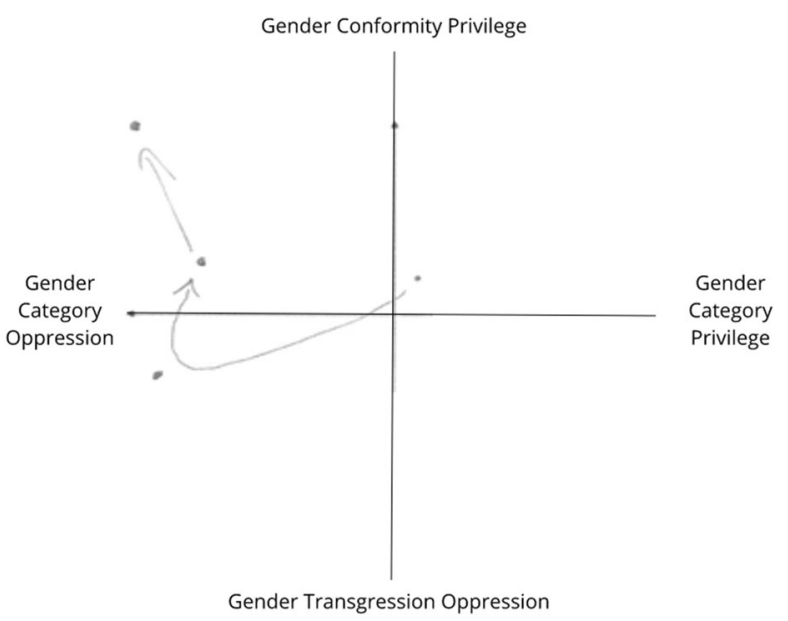

Fig. 4 Amy's placement on the DGO since graduating secondary school 
Amy saw the relative increase in gender category oppression as a small price to pay for the lifting of gender dysphoria and the gender transgression oppression she experienced from not performing "male" well enough to fit society's standards.

In study 2, although the DGO was not utilized, Charles was highly aware of the privilege of being a man in engineering. Charles described how being "a woman in engineering was awful and sexist." Charles described his experiences presenting as a woman in engineering where other men completely ignored and would not even acknowledge his presence. Charles said now that he presents as a man, "everyone respects me so much and like I could literally be like gravity is 10 and not 9.8 and people would be like, 'yeah that's probably right'." Charles described how he now gets stopped randomly outside of class by classmates asking for help, and other students are now more respectful of his knowledge and expertise. Charles' experience of transitioning during his undergraduate degree is indicative of the lingering atmosphere of gender category oppression in STEM fields. This is the reverse of the process described in study 1 by Hannah, Amy, and others.

The experiences described above are evidence that there is still a culture in many STEM fields in which people who present as women are taken less seriously than people who present as men. When someone assumed to be a woman presents in a masculine fashion, they receive backlash for transgressing gender norms. Letting go of internalized gender-based oppression seems to have an impact that outweighs experiencing gender-based oppression from others, but this does not excuse such oppression. Additionally, the experience of gender-based privilege is relative. For trans women, although presenting as male afforded them more social power (often mitigated by gender transgression oppression), the decrease in social power they experienced when presenting as female was still an improvement because it was not accompanied by gender dysphoria.

\section{Coming out in STEM}

This theme draws primarily from study 2; however, we again provide nuance and complexity by drawing on perspectives from participants in study 1 . Coming out in STEM means that students come to understand and name themselves as queer in STEM environments and may convey that information to others. The ways in which participants described coming out in STEM varied considerably, but included (a) decisionmaking on who to come out to as a student in STEM classrooms, (b) finding queerfriendly faculty, (c) experiencing stress and anxiety related to coming out, and (d) hearing homophobic and transphobic statements from other students. In study 2, Charles and Amber each discussed coming out in STEM, but their lived experiences and descriptions of that process encompassed several relevant differences. Charles, who identified as a straight trans man, discussed how, "The whole purpose of me being trans is so that I never have to come out again." Charles said that being queer is one of the only minorities in which you control its disclosure, but you ended up with this "burden of information control." For Charles, this presented a struggle since he did not want to disclose his trans identity to others, but having a leadership role in LGBTQ+ STEM spaces necessitated his coming out as having a trans identity. This was not an easy process for Charles, who feared people would misgender him and say, "Oh, he is actually a girl." Charles described how he used a form of "vetting" where if he deemed 
a person "safe enough," then he would slowly engage the student in conversations and determine if he would come out to that student. He would ask questions about a student's political affiliation, religiousness, or membership in a fraternity as indicators of acceptance. In the few cases that Charles did disclose his queer identity in STEM, he described hearing homophobic and transphobic statements from other students that created a "minefield" for coming out. As a result, Charles said that he had "very few positive experiences coming out or being queer within my major."

In contrast to Charles, Amber described their coming out processes as a personal journey that was experienced in a very public way. As the only "black guy in heels" on a college campus, they described how people would recognize and discuss their presence on campus through social media, which made a very personal journey of coming out a public experience. Unlike how Charles described the information regulation of disclosing his queer identity, Amber did not feel like they "got a choice" in conveying their queer identity. Due to the sound of their voice and the way they physically present in gender-nonconforming attire (e.g., heels, wig), people automatically attach a stereotype, "Oh, they are probably gay." While Amber did not describe the need for controlling the amount of information about their queer identity with other students, they described the psychological and cognitive stress induced by being in STEM spaces while presenting in gender-nonconforming ways. In one instance, Amber recounted the first time they wore a wig to their mathematics class:

I finally got up the courage and we are going to do this ...which was super terrifying... Like you don't have to make any kind of eye contact... I walked in and everything and it was super quiet and like super silent and I felt super awkward and if I just go through the motions just like put on a brave face and it will be fine.

Amber shared that although the experience described above turned out well, based on their continued experience of feeling isolated in STEM, they are currently transitioning to a non-STEM major where they feel that their creativity and intersectional identity will be valued.

Coming out was not a universal experience in educational environments or even across STEM fields. For example, in study 1, Reed described the process of deciding how "out" to be in various spaces. While they did not put much thought into their presentation in women's studies spaces, their presentation in agriculture was much more intentional:

That's always an interesting space to exist in. I always feel really, like, some days when I have agriculture classes - I always make a decision of whether or not to dress super queer for that space, or to dress down as more feminine. Which as a genderfluid person anyway, I'm like, eh, who ... cares.

Reed also described hearing explicitly transphobic statements from their classmates, such as when someone told them he saw "a transvestite walking out of a building." Reed and Violet both described the typical agriculture students as "good ol' boys" who would go back to their family farms. The majority of these students were "not bad people," but were from conservative religious backgrounds that did not provide them 
with any foundation for how to interact with queer people as equals. Violet made sure to emphasize that "other demographic groups in other fields are less aware of how transphobic and homophobic they can be. And even misogynistic." Kayla described a similar culture in aviation.

\section{Culture of mathematics and STEM}

As this section draws equally from both studies, we indicate the study in which the individual participated by indicating S1 (study 1) or S2 (study 2). Participants described multiple ways in which they conceived of the nature of mathematics and science, often resulting in paradoxical experiences that position STEM as objective and independent of identity, yet exclusionary to non-normative identities. Participants made mention of STEM as an objective field, one that is often composed of a set of processes focused on facts or rules. For example, Amber (S2) described mathematics as a concrete relationship between numbers, while Juan (S2) described science as having an empirical approach based on measurements and definitions. Jenny (S2) described the nature of physics as the study and definition of increasingly abstracted rules, conveying that science in general is a meritocracy where any individual can succeed based on intellectual achievement. Participants also described mathematics as abstract, theoretical, and logical. Hannah (S1) described mathematics as "some kind of universal law." For Peter (S1), this objectivity was part of the appeal of mathematics, as they "like that sort of certainty."

Even though all the participants described viewing STEM as objective, the ways in which they interpreted this had different implications for how it positioned their queer identity. For instance, Amber (S2) saw STEM as a discipline with a rigid attention to precision, while Juan, Jenny, and Charles (all S2) primarily saw it as a mechanism for understanding the world around them. Amber described STEM as "precise and it needing to be very boxed" and "never changing," which appeared to be at odds with their identity as being queer and gender fluid. Adopting a precision viewpoint of STEM seemed to position Amber's queer identity at odds with the discipline of mathematics. Amber said that mathematics was pretty straightforward and there "is not a whole lot of wiggle room for there to be queer issues or social justice." In contrast, viewing STEM as a mechanism to understand and make sense of the physical world did not seem to result in the same opposition for Charles, Amber, or Juan (all S2). Charles described mathematics as the "fundamental way we understand the world around us," since the world is "chaotic and random." Jenny (S2) said physics allowed her to "completely understand [a situation] or at least being able to completely predict it," yet for her, the process of understanding was also based in curiosity. Viewing STEM as a tool to make sense of the world often aligned with participants' description of their queer identity as allowing them to view the world differently.

Yet this very notion that STEM is objective contributes to and contrasts with the idea that STEM is neutral from identity. Each of the participants in study 2 described STEM as somehow removed from one's personal identity or current events. Jenny (S2) provided a compelling story of her experience in her calculus course directly after the polarizing 2016 USA presidential election: 
My math professor did not say anything... one thing that I am not the biggest fan of about science is this idea that STEM in general exists in a vacuum, like no matter what is happening in the outside world you are a scientist and you have to just keep going....It felt like the world was crumbling and he just kept teaching... could you recognize something above the equations you are writing on this paper... Can you give your students space to process?

Jenny experienced STEM classrooms as often isolated, operating within a vacuum to the external world that excludes the acknowledgment of experiences and emotions of the students within that setting. For Jenny, viewing STEM as neutral from identity does not allow her the space to process her queer identity within the classroom, which contributed to her perception that queer identity in STEM is best characterized as silent.

Charles (S2) said that "when [he is] in STEM, it's only about being in STEM," and that while his brain is accepted in STEM spaces, the essence of his identity does not belong. Charles said that in STEM, there is a false expectation of objectivity that you cannot bring in your personal life, but if you have a "default identity your personal life is involved without anyone questioning it." Juan (S2) specifically addressed the struggle of being queer in the classroom, labeling it a "distraction" yet at the same time recognizing the conflict between the objectivity of STEM and its exclusion of queer identities.

Which is ironic because people say let us not acknowledge being queer because it's a distraction from the material, but what about for those queer people? When you are not acknowledging it, and being discriminated against, that is a distraction. So, it's a paradox, but we just have to rationalize what really is hurting people, and at the end of the day, and I think there is more damage done when you do not acknowledge identity.

Jenny, Amber, Charles, and Juan (all S2) recognized this paradoxical notion that STEM as a practice is objective, and yet this objectivity has been coupled with structural or institutional factors that have normalized the White straight cisgender male at the center of STEM discourses. Jenny pointed to the historical influence, that "for so much of history, [its] been a field dominated by White cisgender heterosexual men," a comment echoed by Charles suggesting, "we know what the cis- straight White guys' opinion is, we have seen that for a hundred years."

When asked to describe the culture of engineering, the first word Kayla (S1) used was "masculine," closely followed by "conservative." In engineering, Amy (S1) emphasized that sexism was worst when the topic was mathematical: "When it came to mathematics, that tended to be what was the most sexist. ... As soon as you show an equation, then they don't believe you." Violet (S1) described the culture of mathematics as an academic field as "wildly pretentious and up its own ass." Reed (S1) pointed out that in mathematics, the focus is exclusively on quantitative ways to solve problems, while in science, "The data doesn't have to take [the form] of numbers, or values. It can take [the form] of stories, or people's testimonies, that kind of thing." Because mathematics excludes this type of data, it may have less room for discussion of nonnormative identities than other STEM fields, since such discussions are typically prompted by stories rather than numbers. 


\section{Strategies to foster support and resiliency for queer students}

This section also draws from both studies, so we again indicate the study in which the individual participated (S1 and S2). Participants in these studies displayed a remarkable sense of resilience in their desire to pursue a STEM degree. This sense of resilience was often combined with a desire to pursue STEM because of enjoyment and a belief that they could learn the material given effort. Juan (S2) talked about his own sense of resilience, since he experienced stages where "nobody believes in you" and you must "believe in yourself" to succeed in STEM. Juan showcased his resilience and desire to find a queer faculty mentor for oSTEM, describing, "not everyone saw the rationale in creating a space for queer in STEM. So that was so discouraging. I was so angry. But that fortunately lit a fire under me." Charles (S2) and Amber (S2) described how they had been successful in STEM despite all of the challenges and that they would push back against anyone who would try to pressure them.

Participants in study 2 were recruited based on their affiliation with the oSTEM group, which was an important factor in supporting them in pursuing their STEM degree. Charles (S2), who is the president of an oSTEM chapter, described that the rationale for creating this club was to "encourage minorities to thrive in STEM and give them a space where they are welcome." Amber (S2) commented that having groups like oSTEM makes their life easier since they do not have to be the sole representation of queer students in STEM and that others can be leaders and talk to that experience. Jenny (S2) shared that going to oSTEM and having meetings have helped her develop friendships with other queer students in STEM and that she can now be more open with her queer identity in STEM, which allows other students to know her better.

Violet (S1) described how being queer in STEM could sometimes be an advantage, in that it gave them a different perspective on issues and practical skills. For instance, when giving a presentation as a trans woman, they had to focus on the tone of their voice and how they moved, which are valuable public speaking skills for anyone. They referred to the routine infliction of microaggressions as a source of strength that made them more equipped to deal with other setbacks. They also noted that being queer provides a sense of community with other queer people that they would otherwise lack. Reed (S1) also emphasized the importance of "a level of comfort and community" when there were other people present who understand what it is like to be queer in a STEM field. Importantly, Reed and Violet, who were the most visibly gender-nonconforming participants in study 1, felt the most sense of community with other queer people. Meanwhile, participants who just wanted to live as women and did not see being queer or transgender as a central part of their identity, including Amy, Hannah, and Weirdo (all S1), did not feel the same sense of kinship with their queer colleagues.

While we have highlighted the experiences of oppression here, it is also important to note where it was absent. Weirdo (S1), who left her undergraduate program in computer technology to accept a position at a well-known social media company, found that the company and the city in which it was located were very open and accepting. The company provided mandatory sensitivity 
training for all employees, allowed employees to specify their name and gender, had LGBTQ+ employee resource groups, and generally had a supportive culture.

\section{Discussion}

Our finding that many STEM fields are considered masculine and that women experience sexism (gender category oppression) in these fields is hardly revolutionary, yet still worthy of investigation. Previous research contains evidence that high rates of the "protective paternalism" type of benevolent sexism, such as treating women as if they need more assistance than men, were associated with lower self-efficacy and performance in STEM fields for women (Kuchynka et al. 2018). A masculine culture, including negative stereotypes and perceived bias against women, has a negative effect on female participants' sense of belonging and makes them more likely than their male peers to leave the field (Cheryan et al. 2017; Kugler et al. 2017). Experiencing this type of masculine culture would seem to affect primarily those presenting as women, since that is who is subjected to these types of bias. However, Cech and Waidzunas (2011) suggest that perceived masculinity and femininity are at least as important as perceived gender. Gender bias in STEM extends beyond women to the experiences of queer people, as Yoder and Mattheis (2016) found that STEM fields with more gender parity were also more conducive to queer people's level of comfort being out in those fields. The findings of our studies, which include the experiences of students who have experience presenting as women and as men in STEM fields, are a striking confirmation of the persistence of gender-based bias in many STEM fields.

The persistence of gender category oppression extends to gender transgression oppression, as our participants felt that their queer identities were not welcome in their predominantly male STEM fields. Our participants used several strategies to overcome this feeling of being an outsider in their field. For instance, Juan (S2) advocated for the creation of their own spaces, Violet (S1) positioned their queer identity as a strength, and others communicated dispositions of resilience by overcoming internalized oppression and perceived oppression from others. It may seem to the reader that many of our findings are not specific to STEM or mathematics. However, it is this very separation of classroom experiences from identity that caused our participants to feel as though they did not belong, or at least that not all of their identities were welcome in STEM spaces. We have shown that viewing sexual identity as irrelevant to STEM fields significantly contributes to students' experiences of discrimination.

In addition to highlighting the experiences of queer and transgender students, we demonstrate in our studies that gender and sexual identity are nebulous categories that resist simple definitions and categories. A student's gender identity does not always match their gender presentation, and how others interpret that gender presentation does not always coincide with what was intended. Gender presentation can also change from day to day. This is particularly true for nonbinary students. Furthermore, one's gender identity may impact their described sexual identity (e.g., being a female lesbian) but also can be independent (e.g., queer man or queer woman). Sexual identity is also fluid and changes with time, situation, and relationship status. Sometimes queer identity is a visible identity as in the case of Amber (S2), and other times is the "invisible other" as 
was the case with Charles (S2). Even when there is a clear demarcation between when a student presents as male and when they present as female, their experiences are not always what one would expect. In particular, though participants in these studies presenting as female were considered less competent than those presenting as male, for transgender women, this loss of privilege did not seem like something to be grieved, but celebrated. For these participants, a decrease in their social power felt like a small price to pay for being seen in a way that aligned with their self-image. Depending on the situation, privilege can feel like an insult and oppression like a compliment. This is not to say that we should not seek to end gender-based oppression, but to queer the characterization of privilege and oppression as positive and negative, respectively.

From our findings, we can suggest a variety of strategies to support queer students in postsecondary STEM education. First, there is a need to provide a variety of resources that meet the needs of particular queer students. For example, six of the participants who were among the most visibly gender-nonconforming or queer (Amber [S2], Charles [S2], Jenny [S2], Juan [S2], Reed [S1], and Violet [S1]) all expressed benefits of spaces that foster community among queer STEM students such as oSTEM; however, this was not a universally desired resource. Amy, Hannah, and Weirdo (all S1) did not feel the same sense of kinship with their queer colleagues and did not express a need for such community spaces. At the same time, all of the participants described marginalizing experiences, microaggressions, or discriminatory language in STEM environments. Thus, there is not only a need to provide resources outside the classroom but also a need to address the climate and support within academic STEM spaces to prevent exclusionary experiences. Some practices emerging from educational research that we think are promising for STEM fields include the use of pronouns (MacNamara et al. 2017), addressing discriminatory language in the classroom (Linley et al. 2016), implementing queer-inclusive curriculum (Dubbs 2016; Kellermeier 2002; Rands 2009a, 2013), and providing role models and visibility campaigns (Barres et al. 2017; Esposito 2019; Knezz 2019; Restar and Operario 2019). Furthermore, there is a need to address the pedagogy of STEM fields in order to promote a view of mathematics and science that aligns with a student's queer identity. To accomplish this, we must situate our fields within current discourses and events in order to allow queer students to acknowledge their identity and their bodies in STEM spaces. Doing so would complement the notion put forth by Leyva et al. (2016) that in STEM fields, especially engineering, the technical nature of the field is privileged at the expense of the social and communicative aspects of the discipline, which serves to promote heteronormative masculinity. Breaking down these barriers and emphasizing communication and social skills can serve to support queer students. It also means promoting a view of STEM that is exploratory, fluid, open, and a tool to understand and make sense of the world around us.

\section{Closing remarks}

Researchers must consider the complexities of gender and sexual identity. One way to do this is through use of the DGO tool. Depending on the participants, researchers may want to refer to discrimination rather than oppression, as those not well versed in critical theory may be reluctant to label their experiences as oppression. We also suggest avoiding labeling the left side of the horizontal axis as female and the right 
side as male, instead letting participants decide to what extent binary and nonbinary gender categories experience privilege and/or oppression. The DGO is best used with a particular time frame in mind, such as high school or undergraduate years, in order to elicit more specific responses. Whenever possible, participants should be encouraged to provide anecdotes to accompany their diagram. Some participants may not have previously examined their experiences through a lens of privilege and oppression/ discrimination, and need some time to sit with this perspective before they can provide meaningful answers. Researchers should recognize that the work of unpacking one's gendered experiences and sexual identities can be rather demanding for participants as well as researchers. One technique we have used to help elicit such experiences is providing fictional illustrative vignettes of queer students' experiences (see Leyva 2016) to which participants can react, which allows for comparing and contrasting experiences.

As queer theorists, we tend to deconstruct identities. One of the opportunities we as researchers had in this article was to combine our respective studies to build a richer perspective on the lived experiences of queer students in mathematics. Often, research in this vein can struggle with a limited participant pool; thus, combining our analysis provided explanatory power to understand the phenomena being studied. Regardless of whether other researchers use the same theoretical framework, we urge them to unpack what gender identities and sexual identities mean in their research and for their participants, and how these relate to STEM fields. Gender and sexuality are not simple categories with fixed definitions but are culturally constructed and constantly being renegotiated. In the future, researchers should consider not only the experiences of queer individuals in STEM but also what it means to be queer in each setting.

Funding Support for this work was funded by the National Science Foundation (NSF) under Grant Number 1842470 .

\section{Compliance with ethical standards}

Conflict of interest The authors declare that they have no conflict of interest.

Disclaimer The opinions expressed do not necessarily reflect the views of the NSF.

\section{References}

Anderson, D. L. (2005). A portrait of a feminist mathematics classroom: what adolescent girls say about mathematics, themselves, and their experiences in a "unique" learning environment. Feminist Teacher, 15(3), 175-194.

Barnes, M. (2000). Effects of dominant and subordinate masculinities on interactions in a collaborative learning classroom. In J. Boaler (Ed.), Multiple perspectives on mathematics teaching and learning (pp. 145-169). Ablex.

Barres, B., Montague-Hellen, B., \& Yoder, J. (2017). Coming out: the experience of LGBT+ people in STEM. Genome Biology, 18(1), 1-4. https://doi.org/10.1186/s13059-017-1198-y.

Bilmoria, D., \& Stewart, A. J. (2009). "Don’t ask, don't tell”: the academic climate for lesbian, gay, bisexual, and transgender faculty in science and engineering. NWSA Journal, 21(2), 85-103. https://doi.org/10. 1353/nwsa.0.0077. 
Boaler, J. (1997). Reclaiming school mathematics: the girls fight back. Gender and Education, 9(3), 285-305. https://doi.org/10.1080/09540259721268.

Borman, K., Clarke, C., Cotner, B., \& Lee, R. (2012). Cross-case analysis. In J. L. Green, G. Camilli, \& P. B. Elmore (Eds.), Handbook of complementary methods in education research. Routledge.

Britzman, D. (1995). What is this thing called love? Taboo: The Journal of Cultural Studies and Education, l(Spring 1995), 6593.

Brontsema, R. (2004). A queer revolution: reconceptualizing the debate over linguistic reclamation. Colorado Research in Linguistics, 17(1), 1-17. https://doi.org/10.25810/dky3-zq57.

Butler, J. (1993). Bodies that matter: on the discursive limits of sex. New York: Routledge.

Butler, J. (1999). Gender trouble: feminism and the subversion of identity. Routledge.

Cech, E. A. (2015). LGBT professionals' workplace experiences in STEM-related federal agencies. In ASEE Annual Conference and Exposition, Conference Proceedings (Vol. 122nd ASEE). American Society for Engineering Education. https://doi.org/10.18260/p.24431.

Cech, E. A., \& Waidzunas, T. J. (2011). Navigating the heteronormativity of engineering: the experiences of lesbian, gay, and bisexual students. Engineering Studies, 3(1), 1-24. https://oi.org/10.1080/19378629. 2010.545065 .

Cheryan, S., Ziegler, S. A., Montoya, A. K., \& Jiang, L. (2017). Why are some STEM fields more gender balanced than others? Psychological Bulletin, 143(1), 1-35. https://doi.org/10.1037/bul0000052.

Clandinin, D. J., \& Connelly, F. M. (2000). Narrative inquiry: experience and story in qualitative research. Jossey-Bass.

Cobb, P., \& Yackel, E. (1996). Constructivist, emergent, and sociocultural perspectives in the context of developmental research. Educational Psychologist, 31(3/4), 175-190. https://doi.org/10.1207/ s15326985ep3103\&4 3.

Cooper, K. M., \& Brownell, S. E. (2016). Coming out in class: challenges and benefits of active learning in a biology classroom for LGBTQIA students. CBE Life Sciences Education, 15(3), 1-19. https://doi.org/10. 1187/cbe.16-01-0074.

Corbin, J. M., \& Strauss, A. (1990). Grounded theory research: procedures, canons, and evaluative criteria. Qualitative Sociology, 13(1), 3-21. https://doi.org/10.1007/bf00988593.

Davis, B., \& Sumara, D. (2000). Curriculum forms: on the assumed shapes of knowing and knowledge. Journal of Curriculum Studies, 32(6), 821-845. https://doi.org/10.1080/00220270050167198.

Dubbs, C. (2016). A queer turn in mathematics education research: centering the experience of marginalized queer students. In M. B. Wood, E. E. Turner, M. Civil, \& J. A. Eli (Eds.), 38th annual meeting of the North American Chapter of the International Group for the Psychology of Mathematics Education (pp. 1041-1048). The University of Arizona.

Esposito, L. (2019). People have found the strength to come out after reading other scientists' stories. The Biologist, 65(6), 7.

Forman, E. A. (2003). A sociocultural approach to mathematics reform: speaking, inscribing, and doing mathematics within communities of practice. In J. Kilpatrick, W. G. Martin, \& D. Schifter (Eds.). A research companion in principles and standards for school mathematics (pp. 333-352). NCTM.

Gamson, J. (2000). Sexualities, queer theory, and qualitative research. In N. K. Denzin \& Y. S. Lincoln (Eds.), Handbook of qualitative research (2nd, pp. 347-365). Sage.

Ginsburg, H. P. (1997). Entering the child's mind: the clinical interview in psychological research and practice. Cambridge University Press. https://doi.org/10.1017/CBO9780511527777.

Grunert, M. L., \& Bodner, G. M. (2011). Finding fulfillment: women's self-efficacy beliefs and career choices in chemistry. Chemistry Education Research and Practice, 12(4), 420-426. https://doi.org/10.1039/ c1rp90050a.

Gutiérrez, R. (2013). The sociopolitical turn in mathematics education. Journal for Research in Mathematics Education, 44(1), 37-68. https://doi.org/10.5951/jresematheduc.44.1.0037.

Hughes, B. E. (2018). Coming out in STEM: factors affecting retention of sexual minority STEM students. Science Advances, 4(3), 1-6. https://doi.org/10.1126/sciadv.aao6373.

Johnson, R. B., \& Christensen, L. (2014). Educational research: quantitative, qualitative, and mixed approaches (5th ed.). Sage.

Kellermeier, J. (2002). Statistics in social context: using issues of lesbians, gays, bisexuals and transsexuals in teaching. Transformations: The Journal of Inclusive Scholarship and Pedagogy, 13(2), 27-45.

Kersey, E. (2018). Refracting gender: Experiences of transgender students in postsecondary STEM education (Publication No. 10822977) [Doctoral dissertation, Purdue University]. ProQuest Dissertations Publishing.

Knezz, S. N. (2019). Drawing a new scientist: why I come out to my chemistry class. Journal of Chemical Education, 96, 827-829. https://doi.org/10.1021/acs.jchemed.8b00846. 
Koyama, E. (2003). The transfeminist manifesto. In R. Dicker \& A. Piepmeier (Eds.), Catching a wave: reclaiming feminism for the twenty-first century (pp. 244-259). Northeastern University Press.

Kuchynka, S. L., Salomon, K., Bosson, J. K., El-Hout, M., Kiebel, E., Cooperman, C., \& Toomey, R. (2018). Hostile and benevolent sexism and college women's STEM outcomes. Psychology of Women Quarterly, $42(1), 72-87$.

Kugler, A., Tinsley, C., \& Ukhaneva, O. (2017). Why aren't there more women in STEM fields. Vox. Retrieved from https://voxeu.org/article/why-there-arent-more-women-stem-fields Accessed 28 Mar 2020.

Kumashiro, K. K. (2001). Troubling intersections of race and sexuality: queer students of color and antioppressive education. Rowman \& Littlefield Publishers, Inc.

Lamb, E. (2017). Being a trans mathematician: a Q\&A with Autumn Kent. Scientific American Blog Network. Retrieved from https://blogs.scientificamerican.com/roots-of-unity/q-a-with-autumn-kent/. Accessed 28 Mar 2020.

Lerman, S. (2000). The social turn in mathematics education research. In Multiple perspectives on mathematics teaching and learning (pp. 19-44). Ablex.

Leyva, L. A. (2016). "Mapping the margins [in mathematics]": examining the gendered and racialized intersectionality of mathematics experiences among African American and Latina/o undergraduate students in a large, predominantly white university [Doctoral dissertation, Rutgers University-Graduate School-New Brunswick].

Leyva, L., Massa, J., \& Battey, D. (2016). Queering engineering: a critical analysis of the gendered technical/ social dualism in engineering and engineering education research. Proceedings of the ASEE's 123 ${ }^{\text {rd }}$ Annual Conference \& Exposition. American Society for Engineering Education. https://doi.org/10. 18260/p.26026.

Linley, J. L., Nguyen, D., Brazelton, G. B., Becker, B., Renn, K., \& Woodford, M. (2016). Faculty as sources of support for LGBTQ college students. College Teaching, 64(2), 55-63. https://doi.org/10.1080/ 87567555.2015.1078275.

Lopez, G., \& Chims, N. (1993). Classroom concerns of gay and lesbian students: the invisible minority. College Teaching, 41(3), 97-103. https://doi.org/10.1080/87567555.1993.9926788.

MacNamara, J., Glann, S., \& Durlak, P. (2017). Experiencing misgendered pronouns: a classroom activity to encourage empathy. Teaching Sociology, 45(3), 269-278. https://doi.org/10.1177/0092055X17708603.

Mendick, H. (2006). Masculinities in mathematics. Open University Press.

Nasir, N. S., \& de Royston, M. M. (2013). Power, identity, and mathematical practices outside and inside school. Journal for Research in Mathematics Education, 44(1), 264-287. https://doi.org/10.5951/ jresematheduc.44.1.0264.

Ollerenshaw, J. A., \& Creswell, J. W. (2002). Narrative research: a comparison of two restorying data analysis approaches. Qualitative Inquiry, 8(3), 329-347. https://doi.org/10.1177/10778004008003008.

oSTEM. (2020). About oSTEM. Retrieved from https://www.ostem.org/page/about-ostem.

Pearson, J., Muller, C., \& Wilkinson, L. (2007). Adolescent same-sex attraction and academic outcomes: the role of school attachment and engagement. Social Problems, 54(4), 523-542. https://doi.org/10.1525/sp. 2007.54.4.523.

Pride Index. (2017). Campus pride index: national listing of LGBTQ-friendly colleges \& universities. Retrieved from http://www.campusprideindex.org/. Accessed 3 Mar 2020.

Pryor, J. T. (2015). Out in the classroom: transgender student experiences at a large public university. Journal of College Student Development, 56(5), 440-455. https://doi.org/10.1353/csd.2015.0044.

Rands, K. (2009a). Considering transgender people in education: a gender-complex approach. Journal of Teacher Education, 60(4), 419-431. https://doi.org/10.1177/0022487109341475.

Rands, K. (2009b). Mathematical inqu [ee]ry: beyond 'add-queers-and-stir' elementary mathematics education. Sex Education, 9(2), 181-191. https://doi.org/10.1080/14681810902829646.

Rands, K. (2012). Reframing research on gender and mathematics education: considerations from transgender studies. In T. Y. Tso (Ed.), Proceedings of the 36th Conference of the International Group for the Psychology of Mathematics Education (Vol. 3, pp. 337-344). International Group for the Psychology of Mathematics Education.

Rands, K. (2013). Supporting transgender and gender-nonconforming youth through teaching mathematics for social justice. Journal of LGBT Youth, 10(1-2), 106-126. https://doi.org/10.1080/19361653.2012. 717813.

Rankin, S. R., Weber, G., Blumenfeld, W., \& Frazer, S. (2010). 2010 state of higher education for lesbian, gay, bisexual and transgender people. Campus Pride. Retrieved from www.campuspride.org. Accessed 3 Mar 2020. 
Restar, A. J., \& Operario, D. (2019). The missing trans women of science, medicine, and global health. The Lancet, 393, 506-508. https://doi.org/10.1016/s0140-6736(18)32423-1.

Seidman, I. (2013). Interviewing as qualitative research: a guide for researchers in education and the social sciences (4th ed.). Teachers College Press.

Serano, J. (2013). Excluded: making feminist and queer movements more inclusive. Seal Press.

Stinson, D. W., \& Bullock, E. C. (2012). Critical postmodern theory in mathematics education research: a praxis of uncertainty. Educational Studies in Mathematics, 80(1-2), 41-55. https://oi.org/10.1007/ s10649-012-9386-x.

Strauss, A., \& Corbin, J. (1994). Grounded theory methodology: an overview. In N. K. Denzin \& Y. S. Lincoln (Eds.), Handbook of qualitative research (pp. 273-285). Sage Publications.

Trans Student Educational Resources. (2020). LGBTQ+ definitions. Retrieved from https://www.transstudent. org/definitions. Accessed 10 Feb 2020.

Voigt, M. K. (2020). Queer-Spectrum Student Experiences and Resources in Undergraduate Mathematics. [Doctoral dissertation, UC San Diego]. ProQuest Dissertations Publishing. ProQuest ID: Voigt_ucsd_0033D_19269. Retrieved from https:/escholarship.org/uc/item/7g54x6c7.

Walshaw, M. (2001). A Foucauldian gaze on gender research: what do you do when confronted with the tunnel at the end of the light? Journal for Research in Mathematics Education, 32(5), 471-492. https:// doi.org/10.2307/749802.

Walshaw, M. (2004). Introduction: postmodernism meets mathematics education. In M. Walshaw (Ed.), Mathematics education within the postmodern (pp. 1-11). Information Age Publishing.

Wimberly, G. L. (Ed.). (2015). LGBTQ issues in education: advancing a research agenda. American Educational Research Association. https://doi.org/10.3102/978-0-935302-36-3.

Winkle-Wagner, R. (2010). The unchosen me: race, gender, and identity among Black women in college. John Hopkins University Press. https://doi.org/10.1353/book.3502.

Yin, R. K. (2009). Case study research. Design and methods. Thousand Oaks: SAGE.

Yoder, J. B., \& Mattheis, A. (2016). Queer in STEM: workplace experiences reported in a national survey of LGBTQA individuals in science, technology, engineering, and mathematics careers. Journal of Homosexuality, 63(1), 1-27. https://doi.org/10.1080/00918369.2015.1078632.

Publisher's note Springer Nature remains neutral with regard to jurisdictional claims in published maps and institutional affiliations. 